\title{
Design of Optimal Stable Digital IIR Filters Using Hybrid Differential Evaluation
}

\author{
Balraj Singh \\ Department of Electronics \& Communication Engineering, \\ Punjab Technical University, Giani Zail Singh Campus, \\ Bathinda, Punjab, India \\ erbalrajsidhu@rediffmail.com \\ J. S. Dhillon \\ Department of Electrical \& Instrumentation Engineering, \\ Sant Longowal Institute of Engineering \& Technology, \\ Longowal, Punjab, India \\ isdhillonp@yahoo.com \\ Yadwinder Singh Brar \\ Department of Electrical Engineering, Guru Nanak Dev \\ Engineering College, Ludhiana, Punjab, India \\ braryadwinder@yahoo.co.in
}

\begin{abstract}
Material published as part of this publication, either on-line or in print, is copyrighted by the Informing Science Institute. Permission to make digital or paper copy of part or all of these works for personal or classroom use is granted without fee provided that the copies are not made or distributed for profit or commercial advantage AND that copies 1) bear this notice in full and 2) give the full citation on the first page. It is permissible to abstract these works so long as credit is given. To copy in all other cases or to republish or to post on a server or to redistribute to lists requires specific permission and payment of a fee. Contact Publisher@,InformingScience.org to request redistribution permission.
\end{abstract}

This paper proposes the innovative methodologies for the robust and stable design of infinite impulse response (IIR) digital filters using different mutation variants of differential evolution (DE). A multivariable optimization is employed as the design criterion to obtain the optimal stable digital IIR filter which satisfies the different performance requirements like minimizing the magnitude approximation error and minimizing the ripple magnitude in pass band and stop band. DE method is undertaken as a global search technique. Exploratory search is exploited as a local search technique. The proposed ten different mutation variants of DE method enhance the capability to explore and exploit the search space locally as well globally to obtain the optimal filter design parameters. The chance of starting with better solution is improved by comparing the opposite solution. Here both methods are effectively applied for the design of low-pass, and highpass digital IIR filters being multivariable optimization problems. The computational experi-

mental results show that DE methods are superior or at least comparable to other algorithms and can be efficiently applied for higher order filter design.

Keywords: Digital IIR filters, Differential Evolution, Exploratory search, Multi parameter optimization, Opposition based learning. 


\section{Introduction}

A filter is a selective circuit that permits a certain band of frequency to pass while the other frequencies get attenuated. The digital filters can be implemented in hardware or through software and are capable to process both real-time and on-line signals. These days the digital filters are being used to perform many filtering tasks, which previously were performed almost exclusively by analog filters and the digital filters are replacing the traditional role of analog filters in many applications such as image processing, speech synthesis, secure communication, radar processing and biomedical etc. The design of digital infinite impulse response (IIR) filter follows either transformation technique or optimization technique. Using the transformation techniques (Oppenheim, Schafer, \& Buck, 1999), Butterworth, Chebyshev and Elliptic function, have been designed. Optimization methods have been applied whereby performance for the design of digital IIR filters is measured in terms of the magnitude error, and ripple magnitudes (tolerances) of both pass-band and stop-band.

Jiang \& Kwan (2009) has designed the IIR filter by having stability constraint and employs an iterative second-order cone programming method. The simultaneous design in magnitude and group delay has been discussed by Cortelazzo and Lightener (1984). For designing problem of IIR filter in a convex form, the semi-definite programming relaxation technique (Jiang \& Kwan, 2010) has been applied. Being a sequential design procedure, the algorithm finds a feasible solution within a set of relaxed constraints. However, non-linear and multimodal nature of error surface of IIR filters, conventional gradient-based design may easily get stuck in the local minima of error surface. The draw backs of gradient methods, have been conquered by various researchers by applying modern heuristics optimization algorithms such as genetic algorithms (Harris, \& Ifeachor, 1998; Li \& Yin, 1996; Ng, S. C., Chung, C. Y., Leung, S. H., \& A. Luk, 1994; Tang, Man, Kwong, \& Liu, 1998; Uesaka, K., \& Kawamata, M., 2000; Vanuytsel, Boets, Biesen, \& Temmerman, 2002; Zhang, Jin, \& Jin, 2003), particle swarm optimization (PSO) (Sun, Xu, \& Feng, 2004), seeker- optimization- algorithm -based evolutionary method (Dai, Chen, \& Zhu, 2006), simulated annealing (SA) (Chen, Istepanian, \& Luk (2001), tabu search (Kalinli, \& Karaboga, 2005), ant colony optimization (Karaboga, Kalinli, \& Karaboga, 2004), immune algorithm (Tsai \& Chou, 2006) etc. for the design of digital filters.

Evolutionary algorithms (EAs) are based on the mechanics of natural selection and genetics. Genetic algorithms are one example of EAs. The optimization methods based on genetic algorithms are only capable of searching multidimensional and multimodal spaces. These are also able to optimize complex and discontinuous functions (Tang et al., 1998). The digital IIR filter can be structured such as cascade, parallel, or lattice. The low-pass, high-pass, band-pass, and band-stop filters can be independently designed. To design the digital IIR filters genetic algorithm has been applied by Tang et al. (1998). The genetic methods are normally compromised because of their very slow convergence. When the number of the parameters is large, these may trap in the local optima of objective function and there are numerous local optima (Renders \& Flasse, 1996). The hybrid Taguchi genetic algorithm has been applied by Tsai, Chou, \& Liu (2006) for design of optimal IIR filters. With hybrid Taguchi genetic algorithm approach, the combination of the traditional genetic algorithms, which has a powerful global exploration capability, is applied with the Taguchi method. Hence, it is necessary for further developing an efficient heuristic algorithm so as to design the optimal digital IIR filters.

Taguchi-immune algorithm (TIA) is based on the approach that integrates immune algorithm and Taugchi method (Tsai et al., 2006). Yu and Xinjie(2007) have proposed cooperative coevolutionary genetic algorithm for digital IIR filter design. For finding the lowest filter order, the magnitude and the phase response has been considered. The structure and the coefficients of the digital IIR filter have been coded separately. For keeping the diversity, the simulated annealing has been applied for the coefficient species, but to arrive at global minima (Chen et al., 2001), it 
may require too many function evaluations. The seeker-optimization-algorithm based evolutionary method has been implemented for digital IIR filters by Dai et al. (2006). Kaur, Patterh, \& Dhillon (2012) have given design of optimal stable digital IIR filters by applying hybrid optimization algorithms. In another attempt, they have applied the heuristic search methods for the digital IIR filter design (Kaur, Patterh, Dhillon, \& Singh, 2012).

In the literature, there are various methods with which the optimization problem under different conditions is addressed. Based on the type of the search space and the objective function optimization methods are classified. Due to the time-consuming computer simulation or expensive physical experiments, the evaluation of candidate solutions could be computationally and/or financially expensive in IIR filter design problems. Therefore, a method is of great practical interest if it is able to produce reasonably good solutions within a given budget on computational cost/time.

The intent of this paper is to explore the performance of different mutation variants of differential evolution (DE) method while implementing for the design of IIR digital filters. Moreover, these methods are undertaken as global search techniques and an exploratory search is proposed as a local search technique so that these procedures randomly explore the search space globally as well locally. The values of the filter coefficients are optimized with DE to achieve magnitude error and ripple magnitude as objective functions for optimization problem. Constraints are taken care of by applying exterior penalty method.

The paper is organized in six sections. In the next section IIR filter design problem statement is described. In the third section the solution methodology is briefed. The detail of DE algorithm for designing the optimal digital IIR filters have been described in the fourth section. In the fifth section, the performance of the proposed mutation variants of DE methods have been evaluated and achieved results are compared with the design results given by Tang et al. (1998), Tsai et al. (2006), Tsai, \& Chou, (2006), Kaur, Patterh, \& Dhillon, (2012), and Kaur, Patterh, Dhillon, \& Singh (2012).] for the LP, HP, BP, and BS filters. Finally, the conclusions and discussions are outlined.

\section{IIR Filter Design Problem}

A digital filter design problem determines a set of filter coefficients which meet performance specifications. These performance specifications are (a) pass band width and its corresponding gain, (b) width of the stop-band and attenuation, (c) band edge frequencies, and (d) tolerable peak ripple in the pass band and stop-band. The transfer function of IIR filter is defined below:

$$
H(z)=\frac{\sum_{k=0}^{N} p_{k} z^{-k}}{1+\sum_{j=1}^{M} q_{j} z^{-j}}
$$

where $\mathrm{N}$ and $\mathrm{M}$ give order of filter with $M \geq N$.

The design of digital filter design problem involves evaluation of a set of filter coefficients, $p_{k}$ and $q_{j}$ which meet the performance indices. Several first- and second-order sections are cascaded together [6-7] for realizing IIR filters. In the IIR filter, the coefficients are optimized such that the approximation error function for magnitude is to be minimized. The magnitude response is specified at $K$ equally spaced discrete frequency points in pass-band and stop-band. The multivariable constrained optimization problem is stated as below:

Minimize $f(x)=e(x)$

Subject to the stability constraints:- 


$$
\begin{aligned}
& 1+x_{2 i+1} \geq 0(i=1,2, \ldots, N) \\
& 1-x_{2 i+1} \geq 0(i=1,2, \ldots, N) \\
& 1-x_{l+3} \geq 0(l=2 N+4(k-1)+2, k=1,2, \ldots, M) . \\
& 1+x_{l+2}+x_{l+3} \geq 0(l=2 N+4(k-1)+2, k=1,2, \ldots, M,) . \\
& 1-x_{l+2}+x_{l+3} \geq 0(l=2 N+4(k-1)+2, k=1,2, \ldots, N)
\end{aligned}
$$

The stability constraints are included in the design of casual recursive filters, which are obtained by using the Jury method (1964). Here, $e(x)$ denotes the absolute error and is defined as below:

$$
e(x)=\sum_{i=0}^{K}\left|H_{d}\left(\omega_{i}\right)-\right| H\left(\omega_{i}, x\right)|| .
$$

Desired magnitude response, $H_{d}\left(\omega_{i}\right)$ of IIR filter is given as:

$$
H_{d}\left(\omega_{i}\right)= \begin{cases}1, & ; \text { for } \omega_{i} \in \text { passband } \\ 0, & ; \text { for } \omega_{i} \in \text { stopband }\end{cases}
$$

The cascaded transfer function of IIR filter is denoted by $H(\omega, x)$, involving the filter coefficients like, poles and zeros. Irrespective of the filter type, the structure of cascading type digital IIR filter, is stated as ( $\mathrm{Ng}$, Chung, Leung, \& Luk, 1994)).

$$
H(\omega, x)=x_{1}\left(\prod_{i=1}^{N} \frac{1+x_{2 i} e^{-j \omega}}{1+x_{2 i+1} e^{-j \omega}}\right) \times\left(\prod_{k=1}^{M} \frac{1+x_{l} e^{-j \omega}+x_{i+1} e^{-2 j \omega}}{1+x_{l+3} e^{-j \omega}+x_{l+4} e^{-2 j \omega}}\right)
$$

where $l=2 N+4(k-1)+2$ and vector $x=\left[\begin{array}{lll}x_{1} & x_{2} & \ldots . . x_{S}\end{array}\right]^{T}$ denotes the filter coefficients of dimension $\mathrm{S} \times 1$ with $S=2 N+4 M+1$. The scalar constrained optimization problem is converted into unconstrained multivariable optimization problem using penalty method. Augmented function is defined as:

$$
A(x)=f(x)+r\left(P_{\text {term }}\right)
$$

where

$$
P_{\text {term }}=\sum_{i=1}^{N}\left\langle 1+x_{2 i+1}\right\rangle^{2}+\sum_{i=1}^{N}\left\langle 1-x_{2 i+1}\right\rangle^{2}+\sum_{k=1}^{M}\left\langle 1-x_{l+3}\right\rangle^{2}+\sum_{k=1}^{M}\left\langle 1+x_{l+2}+x_{l+3}\right\rangle^{2}+\sum_{k=1}^{M}\left\langle 1-x_{l+2}+x_{l+3}\right\rangle^{2}
$$

$\mathrm{r}$ is a penalty parameter having large value.

Bracket function for constraint given by Eq. (3) is stated below:-

$$
\left\langle 1+x_{2 i+1}\right\rangle= \begin{cases}1+x_{2 i+1} & ; \text { if }\left(1+x_{2 i+1}\right)<0 \\ 0 & ; \text { if }\left(1+x_{2 i+1}\right) \geq 0\end{cases}
$$

Bracket function for constraint given by Eq. (6) is stated below:-

$$
\left\langle 1+x_{l+2}+x_{l+3}\right\rangle= \begin{cases}1+x_{l+2}+x_{l+3} & \text { if }\left(1+x_{l+2}+x_{l+3}\right)<0 \\ 0 & \text { if }\left(1+x_{l+2}+x_{l+3}\right) \geq 0\end{cases}
$$

Similarly bracket functions for other constraints given by Eq. (4), Eq.(5) and Eq. (7) are undertaken.

\section{Solution Methodology}

Various mutation variants of DE have been undertaken to design IIR digital filters. These methods perform global search and an exploratory search is proposed to perform local search so that global as well as local search is performed simultaneously. Opposition based learning is implemented to improve the chance of starting with better solution by checking the opposite solution. 


\section{Differential Evolution}

Differential Evolution is a population-based stochastic method. It is applied to minimize performance index. Differential evolution uses a rather greedy and less stochastic approach to problem solving in comparison to evolutionary algorithms. DE combines simple arithmetical operators with the classical operators of the recombination, mutation, and selection to evolve from a randomly generated starting population to a final solution (Qin, Huang, \& Sugathan, 2009). Various mutation strategies are available in literature which affects the performance of DE.

\section{Exploratory Move}

In the exploratory move, the current point is perturbed in positive and negative directions along each variable one at a time and the best point is recorded. The current point is updated to the best point at the end of each design variable perturbation may either be directed or random. If the point found at the end of all filter coefficient perturbations is different from the original point, the exploratory move is a success; otherwise, the exploratory move is a failure. In any case, the best point is considered to be the outcome of the exploratory move. The starting point obtained with the help of random initialization is explored iteratively and filter coefficient $x_{i}$ is initialized as follows:

$x_{i}^{n}=x_{i}^{o} \pm \Delta_{i} u_{i}^{j} \quad(i=1,2, \ldots, S ; j=1,2, \ldots, S)$

Where

$$
u_{i}^{j}= \begin{cases}1 & i=j \\ 0 & i \neq j\end{cases}
$$

$S$ denotes number of variables.

The objective function denoted by $A\left(x_{i}^{n}\right)$ is calculated as follows

$$
x_{i}^{n}=\left\{\begin{array}{cc}
x_{i}^{o}+\Delta_{i} u_{i} & ; A\left(x_{i}^{o}+\Delta_{i} u_{i}\right)<A\left(x_{i}^{o}\right) \\
x_{i}^{o}-\Delta_{i} u_{i} & ; A\left(x_{i}^{o}-\Delta_{i} u_{i}\right)<A\left(x_{i}^{o}\right) \\
x_{i}^{o} & ; \text { otherwise }
\end{array}\right.
$$

where $(i=1,2, \ldots, S)$ and $\Delta_{\mathrm{i}}$ is random for global search and fixed for local search. The process is repeated till all the filter coefficients are explored and overall minimum is selected as new starting point for next iteration. The stepwise algorithm to explore filter coefficients is outlined below.

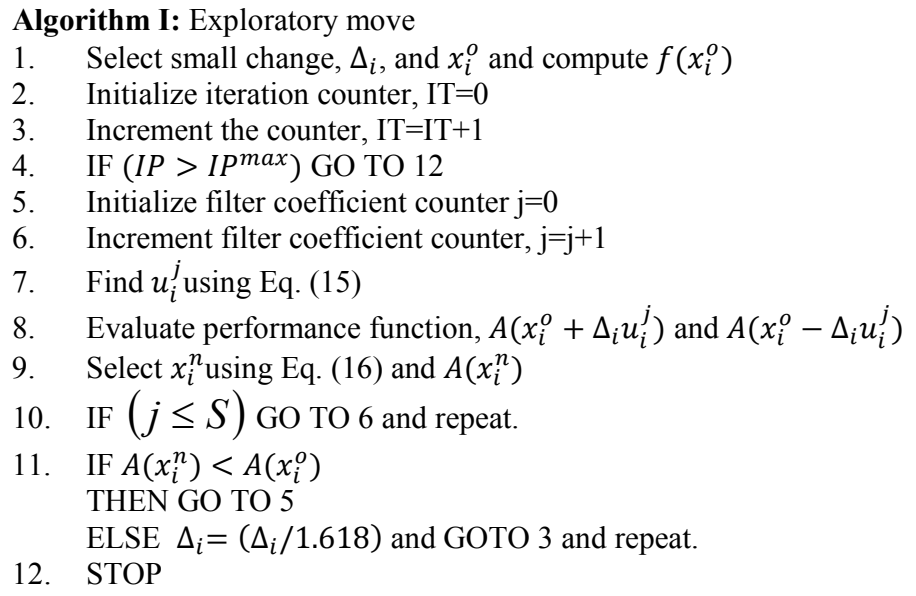




\section{Population Initialization}

Initialize a population $x_{i j}^{t}(\mathrm{j}=1,2, \ldots, \mathrm{S} ; \mathrm{i}=1,2, \ldots, \mathrm{L})$ individuals with random values generated according to a uniform probability distribution in the S-dimensional problem space. Initialize the entire solution vector population within the given upper and lower limits of the search space.

$x_{i j}^{t}=x_{j}^{\min }+\operatorname{rand}()\left(x_{j}^{\max }-x_{j}^{\min }\right)$

$(j=1,2, \ldots, S ; i=1,2, \ldots, L)$

The vector population may violate inequality constraints. This violation is corrected by fixing them either at lower or at upper limit.

\section{Opposition-Based Learning}

Evolutionary optimization methods start with some initial solutions and try to improve them toward some optimal solution(s). The process of searching terminates when some predefined criteria are satisfied. In the absence of prior information about the solution, it is usually started with random guesses. The computation time, among others, is related to the distance of these initial guesses from the optimal solution. It can improve the chance of starting with a better solution by simultaneously checking the opposite solution (Tizhoosh, 2009). By doing this, the better one either guess or opposite guess can be chosen as an initial solution. As per the probability theory, $50 \%$ of the time, a guess is farther from the solution than its opposite guess (Rahnamayan, Tizhoosh, \& Salama, 2008). Therefore, starting with the closer of the two guesses as judged by its objective function has the potential to accelerate convergence. The same approach can be applied not only to initial solutions but also continuously to each solution in the current population (Rahnamayan, et al. 2008).

$x_{i+L, j}^{t}=x_{j}^{\min }+x_{j}^{\max }-x_{i j}^{t}$

$(\mathrm{j}=1,2, \ldots, \mathrm{S} ; \mathrm{i}=1,2, \ldots, \mathrm{L})$.

where $x_{j}^{\min }$ and $x_{j}^{\max }$ are lower and upper limits of filter coefficients.

\section{Evaluation of the Individual Population}

The goal is to minimize the objective function. The elements of parent/offspring $x_{i j}^{t}$ may violate constraint. A penalty term is introduced in the objective function to penalize its objective function value. Objective function is changed to the following generalized form:

$$
\begin{aligned}
& A_{i}\left(x_{i j}\right)=e_{i}\left(x_{i j}\right)+r\left(P_{\text {term }}\right) \\
& (\mathrm{j}=1,2, \ldots, \mathrm{S} ; \mathrm{i}=1,2, \mathrm{~L}) \\
& \text { where penalty factor is given by Eq. (12) and Eq. (13). }
\end{aligned}
$$

\section{DE for IIR Filter Design}

The different variants of $\mathrm{DE}$ are classified using: $\mathrm{DE} / \alpha / \beta / \delta$. $\alpha$ indicates the method for selecting the parent chromosome that will form the base of the mutated vector. $\beta$ indicates the number of difference vectors used to perturb the base chromosome. $\delta$ indicates the recombination mechanism used to create the offspring population. The bin acronym indicates that the recombination is controlled by a series of independent binomial experiments. The variant implemented here is the DE/rand/1/bin, which involves the following steps and procedures (Das \& Suganthan, 2011). The DE search procedure of the proposed differential evolution method has been outlined below.

ALGORITHM II: Differential Evolution

1 Input data 
2. Generate initial population and apply opposition learning strategy

3. Arrange population in ascending order and select first $\mathrm{L}$ members .

4. Set iteration counter, $\mathrm{t}=0$

5. Increment the iteration counter, $\mathrm{t}=\mathrm{t}+1$

6. Apply mutation operator (variants).

7. Apply recombination operation to compute $U_{i j}^{t+1}$ using Eq.(32).

8. Apply selection operation to compute variable $x_{i j}^{t+1}$ using Eq.(33)

9. Apply exploratory move to improve the population by implementing algorithm 1 .

10. Apply random migration to compute variable $x_{i j}^{t+1}$ using Eq.(34)

11. IF $\left(\mathrm{t}<\mathrm{T}_{\max }\right)$ THEN GOTO 5

12. STOP.

\section{Parameter Setup}

The user selects the key parameters that control the DE, i.e. population size (L), boundary constraints of optimization variables $(\mathrm{S})$, mutation factor $\left(f_{m}\right)$, crossover rate (CR), and the stopping criterion of maximum number of iterations (generations) $\mathrm{T}_{\max }$. The set of real IIR digital filter coefficient $(X)$ of all generators is represented as the population. For a system with $\mathrm{S}$ filter coefficients, the population is represented as a vector of length, S. If there are L members in the population, the complete population is represented as a matrix given below:

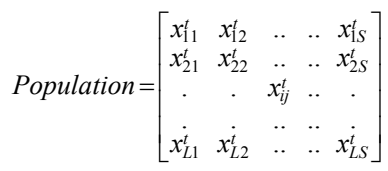

where $X_{i j}^{t}$ is the $j^{\text {th }}$ element of S set of filter coefficients giving $i^{t h}$ individual of a population. Further, $X_{i}^{t}=\left[x_{i 1}^{t}, x_{i 2}^{t}, \ldots, x_{i S}^{t}\right]^{T}$ stands for the position of the ith individual of a population of real valued S-dimensional vectors

\section{Mutation Operation Differential Operation}

Mutation is an operation that adds a vector differential to a population vector of individuals. There are several variations of differential evolution algorithm strategies that can be employed for optimization as mentioned by Sum-Im, Taylor, Irving, and Song (2009). The mutation operation using the difference between two randomly selected individuals may cause the mutant individual to escape from the search domain. If an optimized variable for the mutant individual is outside the search domain, then this variable is replaced by its lower bound or its upper bound so that each individual can be restricted to the search domain. So, the ten mutation variations, which are defined as the following mutation strategies are considered for study:

$$
\begin{aligned}
& \mathrm{DE}-1 ; Z_{i j 1}^{t}=P_{R_{1 j}}^{t}+f_{m}\left(x_{R_{2 j}}^{t}-x_{R_{3 j} j}^{t}\right) \\
& \mathrm{DE}-2 ; Z_{i j 2}^{t}=x_{B j}^{t}+f_{m}\left(x_{R_{1 j} j}^{t}-x_{R_{2} j}^{t}\right) \\
& \mathrm{DE}-3 ; Z_{i j 3}^{t}=x_{i j}^{t}+f_{B}\left(x_{B j}^{t}-x_{i j}^{t}\right)+f_{m}\left(x_{R_{1} j}^{t}-x_{R_{2} j}^{t}\right) \\
& \mathrm{DE}-4 ; Z_{i j 4}^{t}=x_{B j}^{t}+f_{m}\left(x_{R_{1} j}^{t}+x_{R_{2} j}^{t}-x_{R_{3} j}^{t}-x_{R_{4} j}^{t}\right) \\
& \mathrm{DE}-5 ; Z_{i j 5}^{t}=x_{R_{5} j}^{t}+f_{m}\left(x_{R_{1} j}^{t}+x_{R_{2} j}^{t}-x_{R_{3} j}^{t}-x_{R_{4} j}^{t}\right) \\
& \mathrm{DE}-6 ; Z_{i j 6}^{t}=x_{B j}^{t}+f_{m}\left(x_{B j}^{t}-x_{i j}^{t}\right)
\end{aligned}
$$


$\mathrm{DE}-7 ; Z_{i j 7}^{t}=x_{B j}^{t}+f_{m}\left(x_{B j}^{t}-x_{i j}^{t}-x_{R_{1} j}^{t}-x_{R_{2} j}^{t}\right)$

$\mathrm{DE}-8 ; Z_{i j 8}^{t}=x_{B j}^{t}+f_{B}\left(x_{B j}^{t}-P_{x i j}^{t}\right)+f_{m}\left(x_{R_{1} j}^{t}-x_{R_{2} j}^{t}\right)$

$\mathrm{DE}-9 ; Z_{i j 9}^{t}=x_{B j}^{t}+f_{m}\left(x_{B j}^{t}+x_{i j}^{t}-x_{R_{1} j}^{t}-x_{R_{2} j}^{t}\right)$

$\mathrm{DE}-10 ; Z_{i j 10}^{t}=x_{B j}^{t}+f_{m}\left(x_{B j}^{t}-x_{B j}^{t} \mathbf{1}\right)$

$(\mathrm{j}=1,2, \ldots, \mathrm{S} ; \mathrm{i}=1,2, \ldots, \mathrm{L})$

where $t$ is the time (generation); $R_{1}, R_{2}$ and $R_{3}$ are mutually different integers that are also different from the running index, $\mathrm{i}$, randomly selected with uniform distribution from the set $\{1,2, \ldots, i-1, i+1, \ldots, L\} . f_{m}(t)$ is the mutation factor and $f_{m}(t)>0$ is a real parameter, which controls the amplification of the difference between two individuals with indexes $\mathrm{R}_{2}$ and $\mathrm{R}_{3}$ so as to avoid search stagnation and is usually a constant value taken from the range $[0.4,1]$ using chaotic sequence.

The better solution out of the four mutation strategies (DE-11) based on minimum augmented objective function is selected as:

$A_{i}\left(Z_{i j}^{t}\right)=\min \left[A_{i 1}\left(Z_{i j 1}^{t}\right), A_{i 2}\left(Z_{i j 2}^{t}\right), A_{i 3}\left(Z_{i j 3}^{t}\right), A_{i 6}\left(Z_{i j 6}^{t}\right)\right]$

$Z_{i}^{t}=\left[Z_{i 1}^{t}, Z_{i 2}^{t}, \ldots, Z_{i S}^{t}\right]^{T}$ stands for the position of the ith individual of a mutant vector.

\section{Recombination Operation}

Recombination is employed to generate a trial vector by replacing certain parameters of the target vector by the corresponding parameters of a randomly generated donor vector.

For each vector, $Z_{i}^{t+1}$, an index $\mathrm{R}_{5}(\mathrm{i}) \in\{1,2, \ldots, \mathrm{S}\}$ is randomly chosen using a uniform distribution, and a trial vector, $U_{i}^{t+1}=\left[U_{i 1}^{t+1}, U_{i 2}^{t+1}, \ldots, U_{i S}^{t+1}\right]^{T}$

$$
U_{i j}^{t+1}= \begin{cases}Z_{i j}^{t} & \text { if }\left(R_{4}(j) \leq C R\right) \text { or }\left(j=R_{5}(i)\right) \\ P_{i j}^{t} & \text { if }\left(R_{4}(j)>C R\right) \text { or }\left(j \neq R_{5}(i)\right)\end{cases}
$$

$(\mathrm{j}=1,2, \ldots, \mathrm{S} ; \mathrm{i}=1,2, \ldots, \mathrm{L})$.

Where $R_{4}(j)$ is the jth evaluation of a uniform random number generation with $[0,1]$. CR is the crossover or recombination rate in the range $[0,1]$. Usually, the performance of a DE algorithm depends on three variables: the population size, the mutation factor $f_{m}(t)$ and the CR.

\section{Selection Operation}

Selection is the procedure whereby better offspring are produced. To decide whether the vector $U_{i}^{t+1}$ should be a member of the population comprising the next generation, it is compared with the corresponding vector $X_{i}^{t}$. Thus, if $A$ denotes the objective function under minimization, then

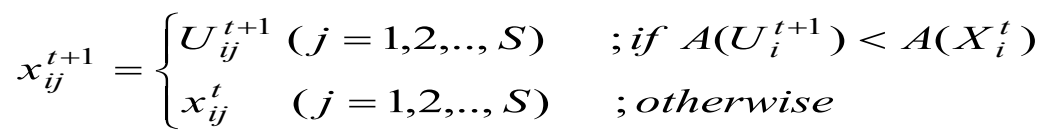

$(\mathrm{i}=1,2, \ldots, \mathrm{L})$

In this case, the objective $\mathrm{A}_{\mathrm{j}}$ of each trial vector $U_{i j}^{t+1}$ is compared with that of its parent target

vector $x_{i j}^{t}$. If the augmented objective function, $\mathrm{A}_{\mathrm{j}}$ of the target vector $x_{i j}^{t}$ is lower than that of the trial vector, the target is allowed to advance to the next generation. Otherwise, a trial vector replaces the target vector in the next generation. 


\section{Migration Operator}

The population diversity and its exploration of the search space are rapidly decreased, and the clustered individuals cannot reproduce newly better individuals by mutation and crossover. In order to increase the exploration of the search space and decrease the selection pressure for a small population, it is randomly selected $0.2 \mathrm{~L}$ individuals to start migration operation.

The $j^{\text {th }}$ gene of the $i^{\text {th }}$ individual is randomly regenerated as follows (Vanuytsel et al., 2002):

$$
x_{i j}^{t+1}=\left\{\begin{array}{l}
x_{b j}^{t+1}+R_{i}\left(x_{j}^{\min }-x_{b j}^{t+1}\right) \text { if } \delta<\frac{x_{b j}^{t+1}-x_{j}^{\min }}{x_{j}^{\max }-x_{j}^{\min }} \\
x_{b j}^{t+1}+R_{i}\left(x_{j}^{\max }-x_{b j}^{t+1}\right) \text { if otherwise }
\end{array}\right.
$$

where $x_{b j}^{t+1}$ is the best individual. $\mathrm{R}_{\mathrm{i}}$ and $\delta$ are uniform random number.

\section{Design and Comparison of IIR Filters}

The design of cascaded digital IIR filter has been implemented. The filter coefficients have been evaluated by applying different mutation variants of DE method. The low pass (LP) and high pass (HP), digital filters have been considered for the design. The design conditions for these filters are given in Table 1.

Table No.1

Design conditions for LP, HP, BP and BS filters.

\begin{tabular}{|c|c|c|c|}
\hline Filter type & Pass-band & Stop-band & $|H(\omega, x)|$ \\
\hline Low-Pass(LP) & $0 \leq \omega \leq 0.2 \pi$ & $0.3 \pi \leq \omega \leq \pi$ & 1 \\
\hline High-Pass(HP) & $0.8 \pi \leq \omega \leq \pi$ & $0 \leq \omega \leq 0.7 \pi$ & 1 \\
\hline
\end{tabular}

To design digital IIR filter, 200 equally spaced points are set within the frequency domain $[0, \pi]$, such that the number of discrete frequency points in Eq. (8), comes out 182 for the LP and HP filters, along with prescribed pass-band and stop-band frequency range is given in Table 1 . The ripple magnitudes of pass-band and stop-band are given by $\delta_{1}(x)$ and $\delta_{2}(x)$, respectively (Lightner \& Director, 1981). Ripple magnitudes are defined as:

$$
\begin{aligned}
& \delta_{1}(x)=\max _{\omega_{i}}\left\{H\left(\omega_{i}, x\right) \mid\right\}-\min _{\omega_{i}}\left\{H\left(\omega_{i}, x\right) \mid\right\} ; \omega_{i} \in \text { passband } \\
& \text { and } \\
& \delta_{2}(x)=\max _{\boldsymbol{\omega}_{i}}\left\{H\left(\omega_{i}, x\right) \mid\right\} ; \omega_{i} \in \text { stopband }
\end{aligned}
$$

\section{Parameters for DE}

For LP, and HP digital IIR filters ten different mutation variants of DE, (DE-1 to DE-11) have been applied to access the effect on performance of DE. For each mutation the value of $\mathrm{M}$ and $\mathrm{N}$ has been varied from $(2,2)$ to $(7,7)$ for LP filter and HP filter, The maximum number of iterations has been taken as 100 for all eleven mutant variants of DE. The maximum migration value is 50 . The mutation ratio, $\mathrm{f}_{\mathrm{m}}$ and crossover ratio, $\mathrm{CR}$ has been taken as 0.85 and 0.25 , respectively. The rate of opposition varies between 0 and 1 has been taken as 0.6 Exploratory move is repeated 20 times. For comparison purposes the value of $\alpha$ has been taken 1.618 for all eleven mutation variants of DE. 


\section{Low Pass Filter}

The low pass filter is designed, as per parameters given in Table 1. The algorithm was given 100 runs for all ten mutation variants (DE-1 to DE-10) of DE, along with the four mutation strategies combined together (DE-11) as given in Eq. (31). All eleven DE mutant variants were run for various combinations of $M \& N$ varying from $(2,2)$ to $(7,7)$. The best results obtained from each of the eleven mutations are given in Table 3 along with order number. It is observed from the results given in Table 3 ,that out of the eleven implemented mutation strategies, the mutation strategy number 4 (DE-4), with value of $\mathrm{M} \& \mathrm{~N}$ as $(2,3)$ and having order no 8 gives the best result for LP filter. The coefficients of IIR filter model designed by this mutation strategy (DE-4), for filter order 8 are given in Table 2.

Table No 2

Low Pass Filter Coefficients

\begin{tabular}{|l|l|l|l|}
$X_{1}=+0.903007$ & $X_{2}=-0.564147$ & $X_{3}=1.451793$ & $X_{4}=-0.560768$ \\
\hline$X_{5}=-0.296367$ & $X_{6}=1.415108$ & $X_{7}=-1.255359$ & $X_{8}=+0.541980$ \\
\hline$X_{9}=-0.195037$ & $X_{10}=+0.604557$ & $X_{11}=-1.166718$ & $X_{12}=+0.662336$ \\
\hline$X_{13}=-0.184995$ & $X_{14}=+0.752750$ & $X_{15}=-1.257409$ & $X_{16}=+0.7611914$ \\
\hline
\end{tabular}

Table No. 3

Design Result For LP Filter

\begin{tabular}{|c|c|c|c|c|}
\hline Mutation & Order & Magnitude Error & Pass-band performance & Stop-band performance \\
\hline DE-1 & 8 & 0.97106 & $\begin{array}{c}0.89114 \leq\left|H\left(e^{j \omega}\right)\right| \leq 1.02162 \\
(0.12989)\end{array}$ & $\begin{array}{c}\left|H\left(e^{j \omega}\right)\right| \leq 0.88338 \\
(0.88338)\end{array}$ \\
\hline DE-2 & 8 & 6.05279 & $\begin{array}{c}0.79569 \leq\left|H\left(e^{j \omega}\right)\right| \leq 1.05889 \\
(0.26330)\end{array}$ & $\begin{array}{c}\left|H\left(e^{j \omega}\right)\right| \leq 0.32409 \\
(0.32409)\end{array}$ \\
\hline DE-3 & 10 & 1.52052 & $\begin{array}{c}0.99143 \leq\left|H\left(e^{j \omega}\right)\right| \leq 1.03353 \\
(0.42104)\end{array}$ & $\begin{array}{c}\left|H\left(e^{j \omega}\right)\right| \leq 0.247831 \\
(0.247831)\end{array}$ \\
\hline DE-4 & 8 & 0.773449 & $\begin{array}{c}0.96626 \leq\left|H\left(e^{j \omega}\right)\right| \leq 1.01635 \\
(0.05009)\end{array}$ & $\begin{array}{c}\left|H\left(e^{j \omega}\right)\right| \leq 0.05883 \\
(0.05883)\end{array}$ \\
\hline DE-5 & 16 & 2.03332 & $\begin{array}{c}0.80309 \leq\left|H\left(e^{j \omega}\right)\right| \leq 1.04628 \\
(0.24317)\end{array}$ & $\begin{array}{c}\left|H\left(e^{j \omega}\right)\right| \leq 0.05398 \\
(0.05398)\end{array}$ \\
\hline DE-6 & 16 & 2.37581 & $\begin{array}{c}0.93905 \leq\left|H\left(e^{j \omega}\right)\right| \leq 1.01217 \\
(0.073119)\end{array}$ & $\begin{array}{c}\left|H\left(e^{j \omega}\right)\right| \leq 0.251464 \\
(0.251464)\end{array}$ \\
\hline DE-7 & 9 & 4.05596 & $\begin{array}{c}0.90914 \leq\left|H\left(e^{j \omega}\right)\right| \leq 1.14128 \\
(0.23214)\end{array}$ & $\begin{array}{c}\left|H\left(e^{j \omega}\right)\right| \leq 0.10647 \\
(0.10647)\end{array}$ \\
\hline DE-8 & 8 & 4.62363 & $\begin{array}{c}0.96450 \leq\left|H\left(e^{j \omega}\right)\right| \leq 1.04904 \\
(0.08453)\end{array}$ & $\begin{array}{c}\left|H\left(e^{j \omega}\right)\right| \leq 0.42837 \\
(0.42837)\end{array}$ \\
\hline DE-9 & 11 & 1.174421 & $\begin{array}{c}0.90913 \leq\left|H\left(e^{j \omega}\right)\right| \leq 1.01441 \\
(0.10528)\end{array}$ & $\begin{array}{c}\left|H\left(e^{j \omega}\right)\right| \leq 0.09852 \\
(0.09852)\end{array}$ \\
\hline DE-10 & 21 & 3.27079 & $\begin{array}{c}0.92213 \leq\left|H\left(e^{j \omega}\right)\right| \leq 1.02075 \\
(0.098221)\end{array}$ & $\begin{array}{c}\left|H\left(e^{j \omega}\right)\right| \leq 0.34024 \\
(0.34024)\end{array}$ \\
\hline DE-11 & 21 & 3.66998 & $\begin{array}{c}0.99300 \leq\left|H\left(e^{j \omega}\right)\right| \leq 1.03221 \\
(0.039209)\end{array}$ & $\begin{array}{c}\left|H\left(e^{j \omega}\right)\right| \leq 0.58160 \\
(0.58160)\end{array}$ \\
\hline
\end{tabular}


For low pass filter the results obtained by Hybrid (Kaur, Patterh, \& Dhillon, 2012), Heuristic (Kaur, Patterh, Dhillon, \& Singh, 2012), HGA (Tang et al., 1998), HTGA (Tsai et al., 2006) and TIA (Tsai \& Chou, 2006) with filter order 3 (M and $\mathrm{N}$ taken as 1,1 respectively) are depicted in Table 4 below. It is observed that the results obtained by DE- 4 with $\mathrm{M} \& \mathrm{~N}$ as $(2,3)$ are better than the results depicted by Harris and Ifeachor (1998), Tsai et al. (2006), Tsai and Chou (2006), Kaur, Patterh, and Dhillon (2012), and Kaur, Patterh, Dhillon, and Singh (2012) given in Table 4 for value of $\mathrm{M} \& \mathrm{~N}$ as $(1,1)$ respectively

Table No 4: Results of previous researchers

\begin{tabular}{|c|c|c|c|c|}
\hline Method & Order & Magnitude Error & Pass-band performance & Stop-band performance \\
\hline 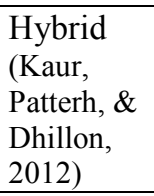 & 3 & 3.7903 & $\begin{array}{c}0.9283 \leq\left|H\left(e^{j \omega}\right)\right| \leq 1.0260 \\
(0.0976)\end{array}$ & $\begin{array}{c}\left|H\left(e^{j \omega}\right)\right| \leq 0.1405 \\
(0.1405)\end{array}$ \\
\hline $\begin{array}{l}\text { Heuristic } \\
\text { (Kaur, } \\
\text { Patterh, } \\
\text { Dhillon, \& } \\
\text { Singh, } \\
\text { 2012) } \\
\end{array}$ & 3 & 4.1145 & $\begin{array}{c}0.9246 \leq\left|H\left(e^{j \omega}\right)\right| \leq 1.0110 \\
(0.0871)\end{array}$ & $\begin{array}{c}\left|H\left(e^{j \omega}\right)\right| \leq 0.1238 \\
(0.1238)\end{array}$ \\
\hline $\begin{array}{c}\text { HGA } \\
\text { (Tang et } \\
\text { al., 1998) } \\
\end{array}$ & 3 & 4.3395 & $\begin{array}{c}0.8870 \leq\left|H\left(e^{j \omega}\right)\right| \leq 1.009 \\
(0.1139)\end{array}$ & $\begin{array}{c}\left|H\left(e^{j \omega}\right)\right| \leq 0.1802 \\
(0.1802)\end{array}$ \\
\hline $\begin{array}{l}\text { HTGA } \\
\text { (Tsai et al., } \\
2006 \text { ) }\end{array}$ & 3 & 4.2511 & $\begin{array}{c}0.90004 \leq\left|H\left(e^{j \omega}\right)\right| \leq 1.000 \\
(0.0996)\end{array}$ & $\begin{array}{c}\left|H\left(e^{j \omega}\right)\right| \leq 0.1247 \\
(0.1247)\end{array}$ \\
\hline $\begin{array}{l}\text { TIA (Tsai } \\
\text { \& Chou, } \\
\text { 2006) }\end{array}$ & 3 & 3.8157 & $\begin{array}{c}0.8914 \leq\left|H\left(e^{j \omega}\right)\right| \leq 1.000 \\
(0.1086)\end{array}$ & $\begin{array}{c}\left|H\left(e^{j \omega}\right)\right| \leq 0.1638 \\
(0.1638)\end{array}$ \\
\hline
\end{tabular}

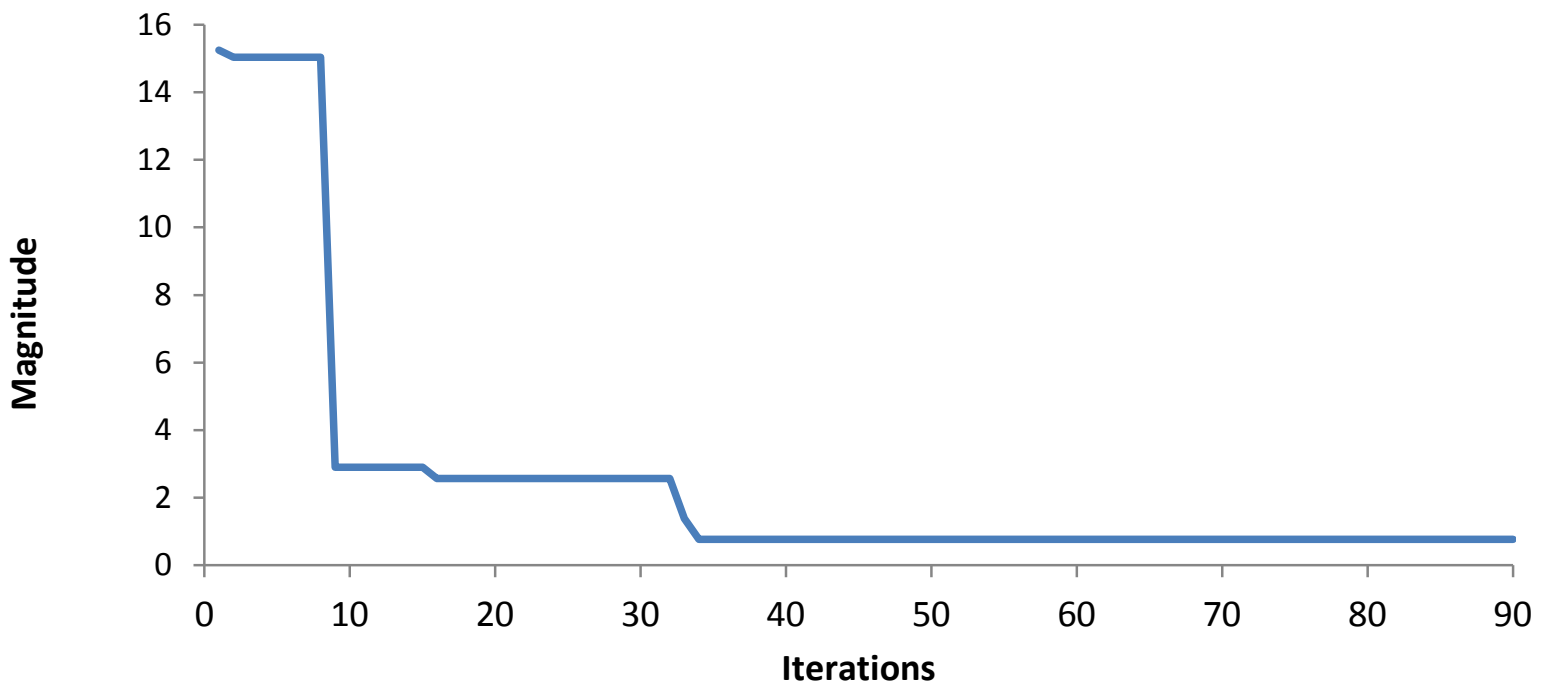

Figure 1: Magnitude versus Iterations for DE-4 with filter order as 8

After 100 runs of each mutation with varying values of $\mathrm{M}$ and $\mathrm{N}$, the best results are depicted in Table 3. Out of these, for the best result obtained from mutation DE-4 with M \& N values as $(2,3)$ and order 8 , the maximum, minimum and average value of magnitude error along with standard deviation for low pass filter are given in Table 14. For the best results obtained from 
DE-4 with order 8, the magnitude versus number of iterations graph for its internal 90 runs is shown in Figure 1. The frequency response of DE-4 with order 8 has been shown in Figure 2 and the corresponding pole-zero plot for DE-4 with order 8 has been shown in Figure 3 .

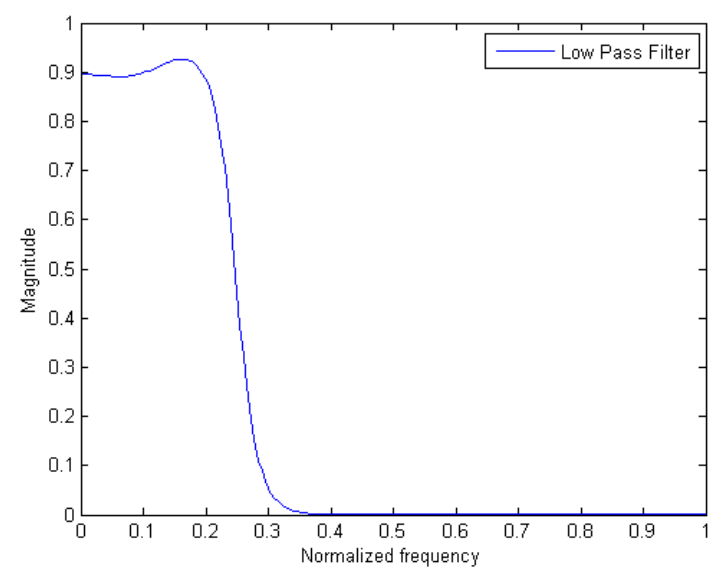

Figure 2 Frequency response of LP filter using DE-4

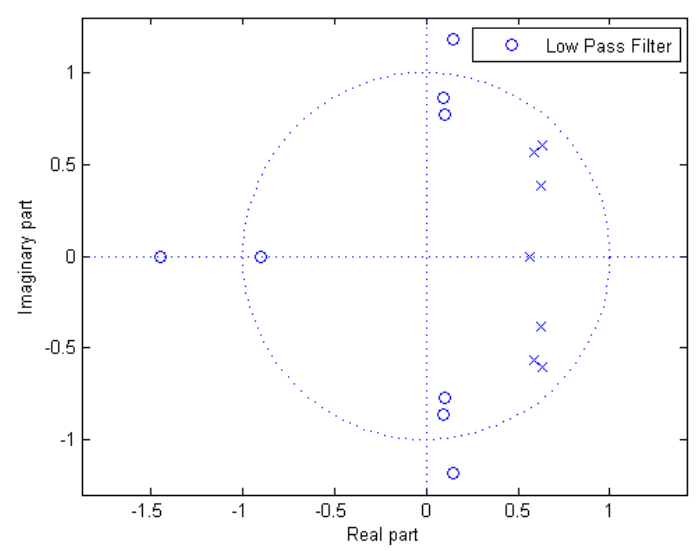

Figure 3 Pole-Zero plot of LP filter using DE-4

\section{High Pass Filter}

The high pass filter is designed as per parameters given in Table 1. The algorithm was given 100 runs for all ten mutation variants (DE-1 to DE-10) of DE along with the four mutation strategies combined together (DE-11) as given in Eq. (31). All eleven DE mutant variants of high pass filter were run for various combinations of $M \& N$ varying from $(2,2)$ to $(7,7)$. The best results obtained from each of the eleven mutation are given in Table 6 along with its order number. 
Table No 5

High Pass Filter Coefficients

\begin{tabular}{|l|l|l|l|}
\hline$X_{1}=-0.040361$ & $X_{2}=+0.649865$ & $X_{3}=-0.315249$ & $X_{4}=+0.626751$ \\
\hline$X_{5}=-0.872858$ & $X_{6}=+0.260470$ & $X_{7}=+0.370351$ & $X_{8}=+0.497021$ \\
\hline$X_{9}=+0.803198$ & $X_{10}=+0.410948$ & $X_{11}=+0.516738$ & $X_{12}=+0.692301$ \\
\hline$X_{13}=1.604773$ & $X_{14}=+0.770023$ & $X_{15}=+0.432912$ & $X_{16}=+0.334600$ \\
\hline$X_{17}=+0.792747$ & $X_{18}=+0.492930$ & $X_{19}=+0.145277$ & $X_{20}=+0.318842$ \\
\hline$X_{21}=-0.889507$ & $X_{22}=+0.889072$ & & \\
\hline
\end{tabular}

It is observed from the results given in Table 6 that out of the eleven implemented mutation strategies, the mutation strategy number 6 (DE-6), with value of M\& $N$ as $(3,4)$ and having order 11 gives the best result for HP filter. The coefficients of IIR filter model designed by this mutation strategy DE-6, for filter order 11 are given in Table 5.

Table No.6

Design Results For HP Filter

\begin{tabular}{|c|c|c|c|c|}
\hline Mutation & Order & $\begin{array}{l}\text { Magnitude } \\
\text { Error }\end{array}$ & Pass-band performance & Stop-band performance \\
\hline DE-1 & 7 & 4.71661 & $\begin{array}{c}0.95667 \leq\left|H\left(e^{j \omega}\right)\right| \leq 1.02733 \\
(0.70663)\end{array}$ & $\begin{array}{c}\left|H\left(e^{j \omega}\right)\right| \leq 0.26693 \\
(0.26693)\end{array}$ \\
\hline DE-2 & 17 & 3.76309 & $\begin{array}{c}0.92255 \leq\left|H\left(e^{j \omega}\right)\right| \leq 1.04976 \\
(0.12720)\end{array}$ & $\begin{array}{c}\left|H\left(e^{j \omega}\right)\right| \leq 0.25695 \\
(0.25695)\end{array}$ \\
\hline DE-3 & 10 & 3.32338 & $\begin{array}{c}0.93565 \leq\left|H\left(e^{j \omega}\right)\right| \leq 1.03233 \\
(0.09667)\end{array}$ & $\begin{array}{c}\left|H\left(e^{j \omega}\right)\right| \leq 0.21574 \\
(0.21574)\end{array}$ \\
\hline DE-4 & 14 & 2.66384 & $\begin{array}{c}0.77406 \leq\left|H\left(e^{j \omega}\right)\right| \leq 1.03402 \\
(0.25996)\end{array}$ & $\begin{array}{c}\left|H\left(e^{j \omega}\right)\right| \leq 0.08972 \\
(0.08972)\end{array}$ \\
\hline DE-5 & 7 & 2.88517 & $\begin{array}{c}0.89707 \leq\left|H\left(e^{j \omega}\right)\right| \leq 1.10768 \\
(0.21060)\end{array}$ & $\begin{array}{c}\left|H\left(e^{j \omega}\right)\right| \leq 0.04362 \\
(0.04362)\end{array}$ \\
\hline DE-6 & 11 & 2.22471 & $\begin{array}{c}0.91528 \leq\left|H\left(e^{j \omega}\right)\right| \leq 1.01675 \\
(0.10146)\end{array}$ & $\begin{array}{c}\left|H\left(e^{j \omega}\right)\right| \leq 0.10209 \\
(0.10209)\end{array}$ \\
\hline DE-7 & 10 & 3.36576 & $\begin{array}{c}0.94582 \leq\left|H\left(e^{j \omega}\right)\right| \leq 1.02236 \\
(0.07653)\end{array}$ & $\begin{array}{c}\left|H\left(e^{j \omega}\right)\right| \leq 0.19688 \\
\quad(0.19688)\end{array}$ \\
\hline DE-8 & 21 & 4.13695 & $\begin{array}{c}0.85498 \leq\left|H\left(e^{j \omega}\right)\right| \leq 1.01243 \\
(0.15744)\end{array}$ & $\begin{array}{c}\left|H\left(e^{j \omega}\right)\right| \leq 0.16092 \\
\quad(0.16092)\end{array}$ \\
\hline DE-9 & 8 & 2.83621 & $\begin{array}{c}0.91645 \leq\left|H\left(e^{j \omega}\right)\right| \leq 1.07140 \\
(0.15494)\end{array}$ & $\begin{array}{c}\left|H\left(e^{j \omega}\right)\right| \leq 0.11302 \\
(0.11302)\end{array}$ \\
\hline DE-10 & 7 & 6.65741 & $\begin{array}{c}0.98191 \leq\left|H\left(e^{j \omega}\right)\right| \leq 1.06433 \\
(0.08242)\end{array}$ & $\begin{array}{c}\left|H\left(e^{j \omega}\right)\right| \leq 0.50469 \\
(0.50469)\end{array}$ \\
\hline DE-11 & 15 & 2.39701 & $\begin{array}{c}0.97889 \leq\left|H\left(e^{j \omega}\right)\right| \leq 1.02005 \\
(0.04116)\end{array}$ & $\begin{array}{c}\left|H\left(e^{j \omega}\right)\right| \leq 0.09198 \\
(0.09198)\end{array}$ \\
\hline
\end{tabular}


For high pass filter the results obtained by Hybrid (Kaur, Patterh, \& Dhillon, 2012), Heuristic (Kaur, Patterh, Dhillon, \& Singh, 2012), HGA (Tang et al., 1998), HTGA (Tsai et al., 2006) and TIA (Tsai \& Chou, 2006) with filter order 3 (M and $\mathrm{N}$ taken as 1,1) are depicted in Table 7 below. It is observed that the results obtained by DE-6 with $\mathrm{M} \& \mathrm{~N}$ as $(3,4)$ are better than the results depicted by Harris and Ifeachor (1998), Tsai et al. (2006), Tsai and Chou (2006), Kaur, Patterh, and Dhillon (2012), and Kaur, Patterh, Dhillon, and Singh (2012) given in Table 6 for values of $\mathrm{M} \& \mathrm{~N}$ as $(1,1)$ respectively.

Table No 7

\begin{tabular}{|c|c|c|c|c|}
\hline Method & Order & $\begin{array}{l}\text { Magnitude } \\
\text { Error }\end{array}$ & Pass-band performance & Stop-band performance \\
\hline $\begin{array}{l}\text { Hybrid } \\
\text { (Kaur, } \\
\text { Patterh, \& } \\
\text { Dhillon, } \\
2012 \text { ) }\end{array}$ & & 3.9724 & $0.9625 \leq\left|H\left(e^{j \omega} \omega\right)\right| \leq 1.0265(0.0639)$ & $\begin{array}{c}\left|H\left(e^{j \omega}\right)\right| \leq 0.1536 \\
(0.1536)\end{array}$ \\
\hline $\begin{array}{l}\text { Heuristic } \\
\text { (Kaur, } \\
\text { Patterh, } \\
\text { Dhillon, \& } \\
\text { Singh, } \\
\text { 2012) }\end{array}$ & & 4.6635 & $0.9584 \leq\left|H\left(e^{j \omega}\right)\right| \leq 1.0080(0.0504)$ & $\begin{array}{c}\left|H\left(e^{j \omega}\right)\right| \leq 0.1477 \\
(0.1477)\end{array}$ \\
\hline $\begin{array}{c}\text { HGA } \\
\text { (Tang et } \\
\text { al., 1998) }\end{array}$ & & 14.507 & $0.9224 \leq\left|H\left(e^{j \omega}\right)\right| \leq 1.00$ & $\begin{array}{c}\left|H\left(e^{j \omega}\right)\right| \leq 0.1819 \\
(0.1819)\end{array}$ \\
\hline $\begin{array}{c}\text { HTGA } \\
\text { (Tsai et } \\
\text { al., 2006) }\end{array}$ & & 4.8372 & $0.9460 \leq\left|H\left(e^{j \omega}\right)\right| \leq 1.00(0.0540)$ & $\begin{array}{c}\left|H\left(e^{j \omega}\right)\right| \leq 0.1457 \\
(0.1457)\end{array}$ \\
\hline $\begin{array}{l}\text { TIA (Tsai } \\
\text { \& Chou, } \\
\text { 2006) }\end{array}$ & & 4.1819 & $0.9229 \leq\left|H\left(e^{j \omega}\right)\right| \leq 1.00(0.0771)$ & $\begin{array}{c}\left|H\left(e^{e \omega}\right)\right| \leq 0.1424 \\
(0.1424)\end{array}$ \\
\hline
\end{tabular}

After 100 runs of each mutation with varying values of $\mathrm{M}$ and $\mathrm{N}$, the best results are depicted in Table 6. Out of these, for the best result obtained from mutation DE-6 with M \& N values as $(3,4)$ and order 11 , the maximum, minimum and average value of magnitude error along with standard deviation for high pass filter are given in Table 14. For the best results obtained from DE-6 with order 11, the magnitude versus number of iterations graph for its internal 90 runs is shown in Figure 4. The frequency response of DE-6 with order 11 has been shown in Figure 5 and the corresponding pole-zero plot for DE- 6 with order 11 has been shown in Figure 6. 


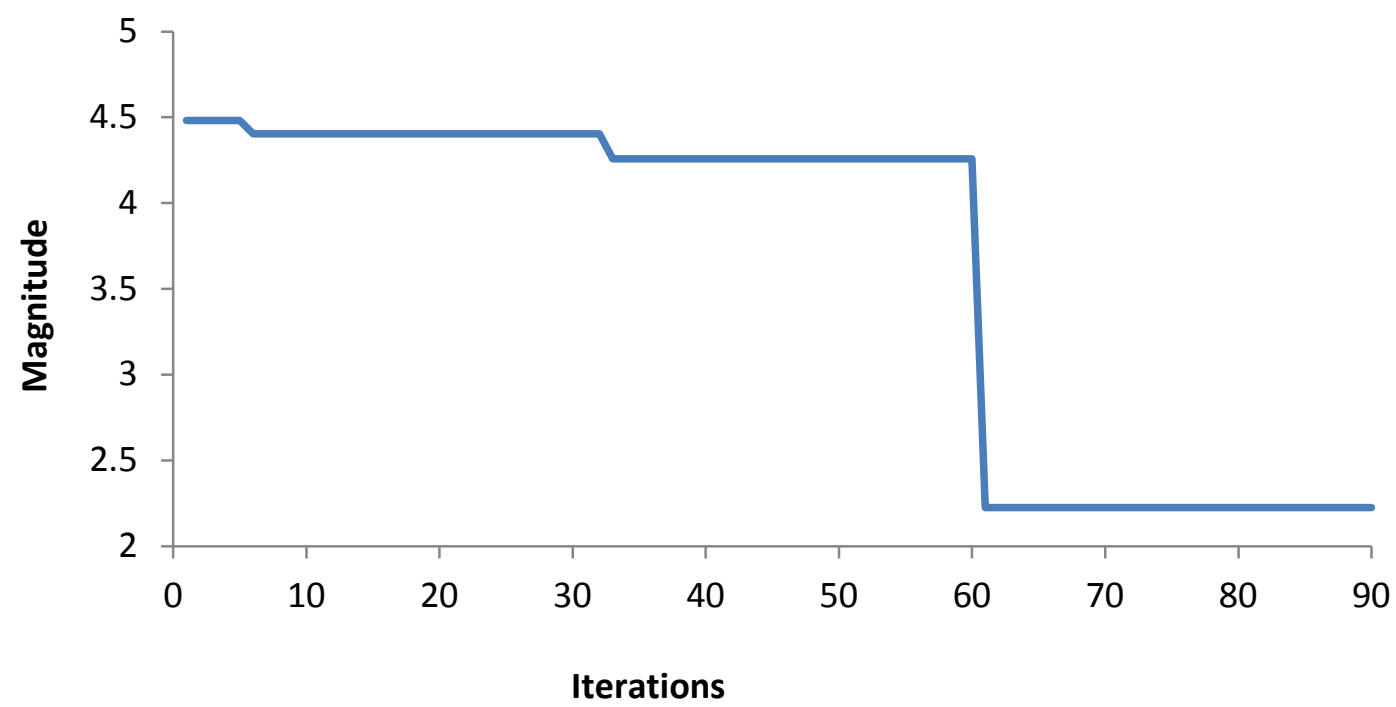

Figure 4 Magnitude versus Iterations for DE-6

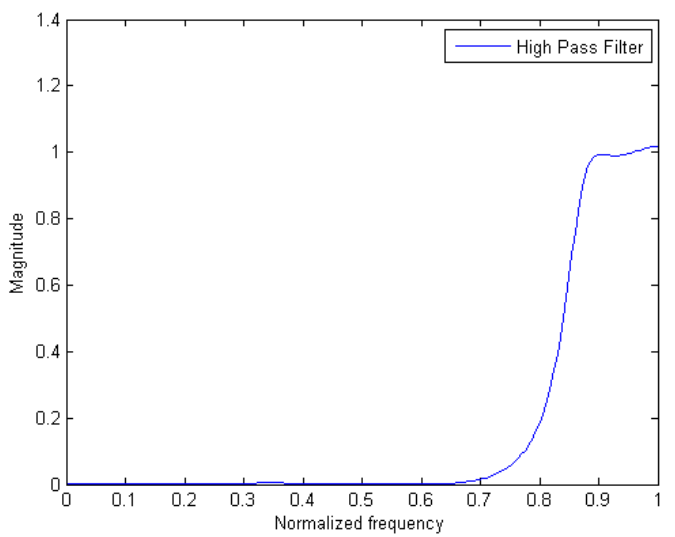

Figure 5 Frequency Response of HP filter using DE-6

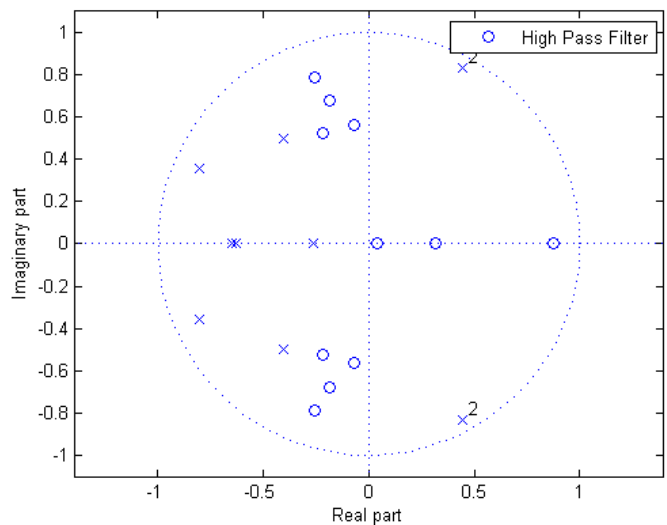

Figure 6: pole zero plot of HP filter using DE-6 
The maximum, minimum and average values of magnitude error along with standard deviation obtained after 100 runs for Low Pass filter with mutation 4 (DE-4) and order 8, for high pass filter with mutation 6 (DE-6) and order 11, have been given below in Table No 14.

Table No 14

Maximum, Minimum, Average values of magnitude error along with Standard Deviation for LP and HP Digital IIR Filters

\begin{tabular}{|c|c|c|c|c|c|l|}
\hline Filter & Mutation & Order & Maximum H & Minimum H & Average & Std Dev \\
\hline LP & DE-4 & 8 & 4.740610 & 0.703530 & 2.706241 & 0.930259 \\
\hline HP & DE-6 & 11 & 5.826424 & 2.224717 & 3.432110 & 0.854246 \\
\hline
\end{tabular}

\section{Conclusion}

This paper proposes the different eleven mutation variants of DE for the design of digital IIR filters whereby locally fine-tuned by exploratory search method. As shown through simulation results, all DE methods work well with an arbitrary random initialization and it satisfies prescribed amplitude specifications consistently. Therefore, the proposed algorithms are useful tool for the design of IIR filters.

On the basis of above results obtained for the design of digital IIR filter, it can be concluded that for low- pass, high-pass, band-pass and band-stop filters, out of the proposed eleven mutation variants of DE method DE-4 and DE-6 methods of DE, respectively are superior to the GA-based method. Further, the proposed DE approach for the design of digital IIR filters allows each filter, whether it is LP and HP digital IIR filter, to be independently designed.

The proposed DE methods are very much feasible to design the digital IIR filters, particularly with the complicated constraints. Parameters tuning still is the potential area for further research. The unique combination of exploration search and global search optimization method that is predator-prey optimization provided by the two types of algorithms yields a powerful option for the design of IIR filters.

\section{References}

Chen, S. Istepanian, R. H., \& Luk, B. L. (2001). Digital IIR filter design using adaptive simulated annealing. Digital Signal Processing, 11(3), 241-251.

Cortelazzo. G., \& Lightner, (1984). Simultaneous design in both magnitude and group-delay of IIR and FIR filters based on multiple criterion optimization. IEEE Transactions on Acoustics, Speech, and Signal Processing, 32(5), 949-967.

Dai, C., Chen, W., \& Zhu, Y. (2006). Seeker optimization algorithm for digital IIR filter design. IEEE Transactions on Industrial Electronics, 57(5), 1710-1718.

Das, S., \& Suganthan, P. N. (2011). Differential evolution: A survey of the state-of-the-art. IEEE Transactions on Evolutionary Computation, 15(1), 4-31.

Harris, S. P., \& Ifeachor, E. C. (1998). Automatic design of frequency sampling filters by hybrid genetic algorithm techniques. IEEE Transactions on Signal Processing, 46(12), 3304-3314.

Jiang, A., \& Kwan, H. K. (2009). IIR digital filter design with new stability constraint based on argument principle. IEEE Transactions on Circuit and Systems-I, 56(3), 583-593.

Jiang, A., \& Kwan, H. K. (2010). Minimax design of IIR digital filters using SDP relaxation technique. IEEE Transactions on Circuits and Systems-I, 57(2). 
Jun Sun, Wei Fang and Wenbo Xu, A Quantum-Behaved Particle Swarm Optimization with diversityguided mutation for the design of two-dimensional IIR digital filters, IEEE Transactions on Circuits and Systems-II, vol. 57, no. 2, pp. 141-145, February 2010.

Jury, I. (1964). Theory and application of the Z-Transform method, New York: Wile.

Kalinli, A., \& Karaboga, N. (2005). A new method for adaptive IIR filter design based on Tabu search algorithm. International Journal of Electronics and Communication (AEÜ), 59(2), 111-117.

Karaboga, N., Kalinli, A., \& Karaboga, D. (2004). Designing IIR filters using ant colony optimization algorithm. Journal of Engineering Applications of Artificial Intelligence, 17(3), 301-309.

Kaur, R., Patterh, M. S., \& Dhillon, J. S. (2012). Design of optimal L1 stable IIR digital filterusing hybrid optimization algorithm. International Journal of Computer Applications, 38(2), 27-32.

Kaur, R., Patterh, M. S., Dhillon, J. S. \& Singh, D. (2012). Heuristic search method for digital IIR filters design. Wseas Transactions on Signal Processing, 8, 121-134.

Li, J. H., \& Yin, F. L. (1996). Genetic optimization algorithm for designing IIR digital filters, Journal of China Institute of Communications, 17, 1-7.

Lightner, M. R., \& Director, S. W. (1981). Multiple criterion optimization for the design of electronic circuits. IEEE Transactions on Circuits and Systems, 28(3), 169-179.

Ng, S. C., Chung, C. Y., Leung, S. H., \& Luk, A. (1994). Fast convergent genetic search for adaptive IIR filtering. Proceeding IEEE International Conference on Acoustic, Speech and Signal Processing, Adelaide, pp. 105-108.

Oppenheim, A. V., Schafer, R. W., \& Buck, J. R. (1999). Discrete-time-signal-processing. Englewood Cliffs, NJ; Prentice Hall.

Qin, A. K., Huang, V. L. \& Sugathan, P. N. (2009). Differential evaluation algorithm with strategy adapter for global numerical optimization. IEEE Transactions on Evolutionary Computation, 13(2), 398-417

Rahnamayan, Tizhoosh, H. R., \& Salama, M. A. (2008). Opposition based differential evolution. IEEE Transactions on Evolutionary Computations, 12(1), 64-79.

Renders, J. M., \& Flasse, S. P. (1996). Hybrid methods using genetic algorithms for global optimization, IEEE Transactions on Systems, Man, and Cybernetics-Part B: vol. 26, no. 2, pp. 243-258, April 1996.

Sum-Im, Taylor, G. A., Irving, M. R., \& Song, Y. H. (2009) Differential evolution algorithm for static multistage transmission expansion planning. IET Generation, Distribution, 3(4), 365-384.

Sun, J., Xu, W. B., \& Feng, B. (2004). A global search strategy of quantum behaved particle swarm optimization. Proceedings of IEEE Conference Cybernetics and Intelligent Systems, Singapore, pp. 111116,200

Tang, K. S., Man, K. F., Kwong, S., \& Liu, Z. F. (1998). Design and optimization of IIR filter structure using hierarchical genetic algorithms. IEEE Transactions on Industrial Electronics, 45(3), 481-487.

Tizhoosh, H. R. (2009). Opposition based reinforcement learning, J advanced computation. Intel intelligent Inform, 10(3), 578-585.

Tsai, J-T., \& Chou, J-H. (2006). Optimal design of digital IIR filters by using an improved immune algorithm. IEEE Transactions on Signal Processing, 54(12), 4582-4596.

Tsai, J-T., Chou, J-H., \& Liu, T-K. (2006). Optimal design of digital IIR filters by using hybrid taguchi genetic algorithm. IEEE Transactions on Industrial Electronics, 53(3), 867-879.

Uesaka, K., \& Kawamata, M. (2000). Synthesis of low-sensitivity second order digital filters using genetic programming with automatically defined functions. IEEE Signal Processing Letters, 7, 83-85.

Vanuytsel, G., Boets, P., Biesen, L. V., \& Temmerman, S. (2002). Efficient hybrid optimization of fixedpoint cascaded IIR filter coefficients. Proceedings of IEEE International Conference on Instrumentation and Measurement Technology, Anchorage, AK, pp.793-797, 2002 


\section{Design of Optimal Stable Digital IIR Filters Using Hybrid Differential Evaluation}

Yu, Y. \& Xinjie, Y. (2007). Cooperative coevolutionary genetic algorithm for digital IIR filter design. IEEE Transactions on Industrial Electronics, 54(3), 1311-1318.

Zhang, G. X., Jin, W. D., \& Jin, F. (2003). Multi-criterion satisfactory optimization method for designing IIR digital filters. Proceedings of International Conference on Communication Technology, Beijing, China, pp. 1484-1490. 